\title{
Predicting Communicative Behavior of Higher Institutions Employees during COVID-19 Pandemic: A Conceptual Assessment
}

\author{
Adamu Abbas Adamu ${ }^{\text {* }}$, Bahtiar Mohamad ${ }^{2}$, Kikin Yuliaty Subarsa Putri \\ ${ }^{1}$ Faculty of Business, Curtin University Malaysia, CDT250, Miri 98009, Malaysia \\ ${ }^{2}$ Othman Yeop Abdullah Graduate School of Business (Oyagsb)/ Institute of Sustainable Growth and Urban Development \\ (ISGUD), Universiti Utara Malaysia, Malaysia \\ ${ }^{3}$ Department of Communication, Faculty of Social, Jakarta State University, Indonesia \\ *Correspondence: adamu.abbas@curtin.edu.my
}

SUBMITTED: 24 October 2021; REVISED: 23 November 2021; ACCEPTED: 23 November 2021

\begin{abstract}
Over the last three decades, a series of research has revealed how strategic communication may have a profound effect on how members of society behave. More precisely, communication theories have documented the media's ability to determine the agenda in society. The situational theory of problem solving is particularly interesting because it explains why and how individual members of society communicate during a problematic situation. This hypothesis has been evaluated in a variety of contexts to determine its efficacy. However, few studies have been conducted to examine the influence of communication from corporations or government to community members. The character of persons, particularly employees' information seeking and sharing behavior, has been significantly overlooked in the context of COVID-19. The purpose of this study is to investigate theoretically how employees process, seek, forward, filter, choose, and exchange information regarding COVID 19.
\end{abstract}

KEYWORDS: COVID 19; communication; higher institution; crisis

\section{Introduction}

Numerous investigations have established that the disease COVID 19 developed in the Chinese city of Wuhan in the Hubei province [1-3]. The plague was initially recognized in late December 2019, when clusters of pneumonia cases with an unknown cause were connected to exposure to a seafood market in the aforementioned province [4]. As a result, on 30th January 2020, the World Health Organization designated COVID-19 a global public health emergency posing a high danger to countries with inadequate health systems [5]. COVID 19 has afflicted countries worldwide to date, with over 720,000 confirmed cases and 33,000 recorded deaths $[6]$.

To restrict the spread of the Virus, countries have implemented stringent measures such as social isolation [7, 8], hand washing, and environmental cleaning. Numerous prior studies examined the effect of communication actions on health-related behavior [9-11]. However, no data on the level of awareness and attitude of Higher Institution Employees (HIE) toward COVID 19 are available. The purpose of this study was to determine the effect of 
communicative actions on HIE knowledge and attitudes toward COVID 19. It has remained unclear how individuals gain access to knowledge on COVID 19 and how credible and prepared they are to apply that knowledge. There are few research on the timing and manner in which individuals process, seek, forward, filter, choose, and exchange information regarding COVID 19. Numerous scientists have established that information seeking is a crucial element in predicting health behavior, which results in a variety of favorable health outcomes [9]. Indeed, the extent to which individuals benefit from health information is largely determined by their ability to obtain, process, and convey the data [10]. Thus, it is critical to examine how HIE get information regarding COVID 19 and how they respond to the information.

Thus, the purpose of this study is to investigate conceptually the extent to which HIE process, seek, forward, filter, choose, and distribute COVID 19 information. Additionally, the study seeks to ascertain the extent to which HIEs are familiar with and supportive of COVID 19. Additionally, this study will examine the variance in HIE knowledge and attitude regarding COVID 19 in relation to demographic and psychographic characteristics. The remainder of the paper is divided into four sections, the first of which defines communicative activity. This leads to a discussion of the six critical dimensions of communicative action in the second section, which include information defending, information permitting, information forwarding, information sharing, information seeking, and information attending, while the third section examines the concept of knowledge regarding COVID-19. The conclusion connects these topics in terms of theory growth, professionalism, and future research directions.

\section{Communicative action}

According to the concepts of situational theory of problem solving (STOP), communicative action refers to a problem solver's increased communication activity in information gathering, selection, and dissemination while he or she engages in issue solving [12]. According to Grunig [13], communicative activity in issue solving occurs as a result of individuals' problem solving practices as a management tool. It is a second-order construct with six antecedents: information defense, information permitting, information forwarding, information sharing, information seeking, and information attending [14]. Similarly, the six communication factors are incorporated into three communication behaviors: information collection, information selection, and information transmission [12]. Simply said, the more effort an individual devotes to problem solving, the more acquisitive of information about the problem, selective in how the information is handled, and transmissive in how it is shared with others [12].

According to the STOP, when individuals recognize an incident as a fundamental problem that must be addressed, they will devote cognitive and communicative resources to resolving it [15]. The STOP's primary theoretical premise is that a specific condition motivated to solve a problem would amplify communicative action related with the problematic circumstance [16]. Additionally, the theory postulates that participation in the six information behaviors associated with resolving a frightening circumstance is a result of an individual's perspective on the condition, motivation to solve the issue, and triggering of cognitive frameworks [15]. The following section will address the preconditions for communicative activity. 


\subsection{Information selection behaviors: permissive and forefendin}

According to Kim and Grunig [13], during problem solving, a problem solver develops two types of information selectivity: information forefending and information allowing. Information selection behavior, in particular, relates to an individual's degree of control over acquiring and disseminating information in order to conserve cognitive resources for problem solving or to elevate his or her selected solution and end states [15]. Equally crucial is the fact that information permitting and information forefending are not mutually exclusive. More precisely, an individual can be tolerant of nearly all pertinent information and points of view from a variety of sources, including those that contradict his or her initial point of view [14]. (Kim et al., 2011). As a result, Kim and Grunig [12] concluded that the more deliberate an individual is when confronted with an issue, the more likely the individual will engage in information allowing and information forefending behavior.

\subsection{Information acquisition behaviors: Information seeking and information attending}

Over the last decade, research has established a link between information seeking and attendance and information acquisition [12,17]. The acquisition of information has been emphasized as being centered on communicative behavior in relation to the many types of information utilized to solve problems [15]. On the one hand, information seeking is a sort of active communication that involves scanning the surroundings for information about a certain subject. On the other hand, information attending refers to an inert communication style that results in the inadvertent detection and persistent processing of information [18]. With this in mind, Kim et al. [14] shown that an active issue solver actively searches out information and pays attention to it, whereas an inactive problem solver may work on knowledge only when it is presented to him or her.

\subsection{Information transmission behaviors: Information forwarding and information sharing}

According to a number of academics, information can be sent in two distinct ways [14]. Inactive information transmission is the sharing of information in response to a request for one's perspective on a subject. In comparison, an active information transmitter sends information proactively, regardless of whether someone requests it [12]. When an individual is unsure of the solution to an issue, previous research indicates that he or she frequently considers the utility of exploiting collective behaviors by teaching others about what might happen if the problem is not handled [15]. In general, the more active communicator is one who shares and forwards information [14].

\section{Knowledge about COVID19}

Several decades of research have revealed that a lack of understanding and awareness about diseases has been linked to the rapid development of infectious diseases [19,20]. Similarly, effective prevention and control have been observed to benefit from all stakeholders' compliance with preventive information [21]. Similarly, studies have found that when employees perceive an infectious disease in their work environment, their performance suffers [20]. Other research has revealed disparities in the level of knowledge and attitude toward COVID 19 between those with high and poor socioeconomic backgrounds [22]. 
According to studies, non-medical subgroups have a limited awareness of the nature of COVID 19 [23]. Earlier investigations demonstrate that more than $80 \%$ of COVID 19 patients presented with modest symptoms and healed without medical intervention, while nearly $20 \%$ of infected cases developed a serious sickness such as multi-organ failure, shortness of breath, fever, and a projected $2 \%$ fatality [24]. This demonstrates the importance of conducting more research on the attitudes and knowledge of various stakeholder groups.

Kim and Hong's study discovered that problem recognition, involvement, and constraint recognition were all significantly associated with persons' anger and dread regarding the spread of COVID-19. Surprisingly, the data indicate that fear had a significant effect on situational motivation in problem-solving and information-seeking actions such as advancing and permitting [25]. Similarly, other research use situational theory of problem solving to examine the effects of fear and a favorable organization-public relationship on behavioral intentions to follow Centers for Disease Control and Prevention recommendations. Fear and a favorable organization-public relationship were found to have a positive effect on individual information transmission, acquisition, and willingness to follow the Centers for Disease Control and Prevention's guidelines for dealing with infectious diseases [26]. This study demonstrates how situational theory of problem solving can help communication practitioners better grasp the factors that motivate individuals to share information about COVID-19.

\section{Conclusion}

The conceptual model demonstrates how situational theory of problem solving can be used to the setting of health communication to investigate the effect of communication on behavioral intentions during a pandemic. The extent to which the public makes use of information from numerous media in a crisis situation is critical. The epidemic of COVID-19 has emphasized the critical role of effective communication in increasing community members' understanding. However, additional empirical evidence is required to demonstrate the effect on behavioral intentions. Another key component in COVID-19 prevention knowledge and practice is that community members are aware that the novel coronavirus can be prevented by maintaining social distance and frequent handwashing. Nonetheless, there was a significant issue with adapting to this knowledge and practice. This demonstrates the importance of additional research on the behavioral intentions of individual members of society.

\section{Competing Interest}

The authors declare no financial or non-financial competing interests.

\section{References}

[1] Lu, H.1; Stratton, C.W.; Tang, Y.W. (2020). Outbreak of Pneumonia of Unknown Etiology in Wuhan China: the Mystery and the Miracle. Journal of Medical Virology, 92, 401-402. https://doi.org/10.1002/jmv.25678.

[2] Wang, D.; Hu, B.; Hu, C.; Zhu, F.;Liu, X.; Zhang, J.; Zhao, Y. (2020). Clinical characteristics of 138 hospitalized patients with 2019 novel coronavirus-infected pneumonia in Wuhan, China. Jama, 323, 1061-1069. https://dx.doi.org/10.1001\%2Fjama.2020.1585.

[3] Sia, J.K.M.; Adamu, A.A. (2020). Facing the unknown: pandemic and higher education in Malaysia. Asian Education and Development Studies, 1-13. http://dx.doi.org/10.1108/AEDS-052020-0114. 
[4] Wang, C.; Pan, R.; Wan, X.; Tan, Y.; Xu, L.; Ho, C.S.; Ho, R.C. (2020). Immediate psychological responses and associated factors during the initial stage of the 2019 coronavirus disease (COVID19) epidemic among the general population in China. International Journal of Environmental Research and Public Health, 17, 1729. https://doi.org/10.3390/ijerph17051729.

[5] Sohrabi, C.; Alsafi, Z.; O’Neill, N.; Khan, M.; Kerwan, A.; Al-Jabir, A.; Losifidis, C.; Agha, R. (2020). World Health Organization declares global emergency: A review of the 2019 novel coronavirus (COVID-19). International Journal of Surgery, 76, 71-76. https://doi.org/10.1016/j.ijsu.2020.02.034.

[6] Rajkumar, R.P. (2020). COVID-19 and mental health: A review of the existing literature. Asian Journal of Psychiatry, 52, 102066. https://dx.doi.org/10.1016\%2Fj.ajp.2020.102066.

[7] Yong, S.S.; Sia, J.K.M. (2021). COVID-19 and social wellbeing in Malaysia: A case study. Current Psychology, 12, 1-15. https://doi.org/10.1007/s12144-021-02290-6.

[8] Anderson, R.M.; Heesterbeek, H.; Klinkenberg, D.; Hollingsworth, T.D. (2020). How will country-based mitigation measures influence the course of the COVID-19 epidemic?. The Lancet, 395, 931-934. https://doi.org/10.1016/s0140-6736(20)30567-5.

[9] Shen, H.; Xu, J.; Wang, Y. (2019). Applying situational theory of problem solving in cancer information seeking: A cross-sectional analysis of 2014 hints survey. Journal of health communication, 24, 165-173. https://doi.org/10.1080/10810730.2019.1587111.

[10] Yan, J.; Wei, J.; Zhao, D.; Vinnikova, A.; Li, L.; Wang, S. (2018). Communicating online dietnutrition information and influencing health behavioral intention: The role of risk perceptions, problem recognition, and situational motivation. Journal of Health Communication, 23, 624-633. https://doi.org/10.1080/10810730.2018.1500657.

[11] Kim, J.N.; Lee, S. (2014). Communication and cybercoping: Coping with chronic illness through communicative action in online support networks. Journal of Health Communication, 19, 775794. https://doi.org/10.1080/10810730.2013.864724.

[12] Kim, J.N.; Grunig, J.E. (2011). Problem solving and communicative action: A situational theory of problem solving. Journal of Communication, 61, 120-149. http://dx.doi.org/10.1111/j.14602466.2010.01529.x.

[13] Grunig, J.E. (1997). A situational theory of publics: Conceptual history, recent challenges and new research. In Public Relations Research: An international perspective, $1^{\text {st }}$ ed.; Moss, D., MacManus, T., Vercic, D.; International Thompson Business Press: Haryana, India, Volume 3, pp. 48.

[14] Kim, J.N.; Shen, H.; Morgan, S.E. (2011). Information behaviors and problem chain recognition effect: Applying situational theory of problem solving in organ donation issues. Health Communication, 26, 171-184. https://doi.org/10.1080/10410236.2010.544282.

[15] Chen, Y.R.R.; Hung-Baesecke, C.J.F.; Kim, J.N. (2017). Identifying active hot-issue communicators and subgroup identifiers: Examining the situational theory of problem solving. Journalism \& Mass Communication Quarterly, 94, 124-147. http://dx.doi.org/10.1177/1077699016629371.

[16] Kim, J. N.; Lee, S. (2014). Communication and cybercoping: Coping with chronic illness through communicative action in online support networks. Journal of Health Communication, 19, 775794. https://doi.org/10.1080/10810730.2013.864724.

[17] Shin, K.A.; Han, M. (2016). The role of negative emotions on motivation and communicative action: Testing the validity of situational theory of problem solving in the context of South Korea. Asian Journal of Communication, 26, 76-93. https://doi.org/10.1080/01292986.2015.1083597.

[18] Kim, J.N.; Grunig, J.E. (2011). Problem solving and communicative action: A situational theory of problem solving. Journal of Communication, 61, 120-149. http://dx.doi.org/10.1111/j.14602466.2010.01529.x. 
[19] Kim, S.G. (2015). Healthcare workers infected with Middle Eastrespiratory syndrome coronavirus and infection control. Journal of the Korean Medical Association, 58, 647-654. https://dx.doi.org/10.4178\%2Fepih.e2017052.

[20] Alsahafi, A.J.; Cheng, A.C. (2016). Knowledge, attitudes and behaviours of healthcare workers in the Kingdom of Saudi Arabia to MERS coronavirus and other emerging infectious diseases. International Journal of Environmental Research and Public Health, 13, 1214. https://dx.doi.org/10.3390\%2Fijerph13121214.

[21] Asaad, A.M.; El-Sokkary, R.H.; Alzamanan, M.A.; El-Shafei, M. (2019). Knowledge and attitudes towards Middle East respiratory syndrome-coronavirus (MERS-CoV) among health care workers in south-western Saudi Arabia. East Mediterranean Health Journal, 26, 435-442. https://doi.org/10.26719/emhj.19.079.

[22] Abdelhafiz, A.S.; Mohammed, Z.; Ibrahim, M.E.; Ziady, H.H.; Alorabi, M.; Ayyad, M.; Sultan, E.A. (2020). Knowledge, Perceptions, and Attitude of Egyptians Towards the Novel Coronavirus Disease (COVID-19). Journal of Community Health, 45, 881-890. https://doi.org/10.1007/s10900-020-00827-7.

[23] Modi, P.D.; Nair, G.; Uppe, A.; Modi, J.; Tuppekar, B.; Gharpure, A.S.; Langade, D. (2020). COVID-19 awareness among healthcare students and professionals in Mumbai metropolitan region: a questionnaire-based survey. Cureus, 12, 7514. https://doi.org/10.7759/cureus.7514.

[24] Giao, H.; Han, N.T.N.; Van Khanh, T.; Ngan, V.K.; Van Tam, V.; Le An, P. (2020). Knowledge and attitude toward COVID-19 among healthcare workers at District 2 Hospital, Ho Chi Minh City. Asian Pacific Journal of Tropical Medicine, 13, 260-265. http://dx.doi.org/10.4103/19957645.280396.

[25] Kim, H.J.; Hong, H. (2021). Predicting Information Behaviors in the COVID-19 Pandemic: Integrating the Role of Emotions and Subjective Norms into the Situational Theory of Problem Solving (STOPS) Framework. Health $\quad$ Communication, 1-10. https://doi.org/10.1080/10410236.2021.1911399.

[26] Chon, M.G.; Park, H. (2021). Predicting public support for government actions in a public health crisis: Testing fear, organization-public relationship, and behavioral intention in the framework of the situational theory of problem solving. Health Communication, 36, 476-486. https://doi.org/10.1080/10410236.2019.1700439.

[27] Bekele, D.; Tolossa, T.; Tsegaye, R.; Teshome, W. (2021). The knowledge and practice towards COVID-19 pandemic prevention among residents of Ethiopia. An online cross-sectional study. Plos one, 16, e0234585. https://doi.org/10.1371/journal.pone.0234585. 